\section{俩 Heighten Science \\ P U B L I C I T I O N S Corporation ISSN 2639-6653}

\title{
Chemotherapy Exposure and outcomes of Chronic Lymphoid Leukemia Patients
}

\author{
Josephina G Kuiper ${ }^{1 *}$, Patience Musingarimi², Christoph \\ Tapprich ${ }^{3}$, Fernie JA Penning-van Beest ${ }^{1}$ and Maren Gaudig ${ }^{4}$ \\ 'PHARMO Institute for Drug Outcomes Research, Van Deventerlaan 30-40 - 3528 AE Utrecht, \\ Netherlands \\ 2Janssen Health Economics\&Market Access EMEA, 50-100 Holmers Farm Way, High Wycombe \\ Buckinghamshire HP12 4EG, United Kingdom \\ ${ }^{3}$ Janssen Medical Affairs EMEA, Platz 1, 41470 Neuss, Germany \\ ${ }^{4}$ Janssen Health Economics \& Market Access EMEA, Neuss, Germany
}

*Address for Correspondence: Dr. Josephina G. Kuiper, MSc, PHARMO, Institute for Drug Outcomes Research Van Deventerlaan 30-40, 3528 AE Utrecht, the Netherlands, Tel: +31 (0)30 7440 800; E-mail: josine.kuiper@pharmo.nl

Submitted: 21 April 2017

Approved: 23 June 2017

Published: 26 June 2017

Copyright: @ 2017 Kuiper JG, et al. This is an open access article distributed under the Creative Commons Attribution License, which permits unrestricted use, distribution, and reproduction in any medium, provided the original work is properly cited.

Keywords: Chronic lymphoid leukemia; Chemotherapy exposure; Healthcare utilization; Survival

\section{SUMMARY}

This study describes chemotherapy exposure, healthcare utilization, overall survival (OS) and progressionfree survival (PFS) among patients diagnosed with chronic lymphoid leukemia (CLL). Newly diagnosed CLL patients who received chemotherapy were selected from the Eindhoven Cancer Registry between 1998-2011, linked on a patient-level to the PHARMO Database Network including data on in- and out-patient drug dispensings, hospitalizations and clinical laboratory measurements. Chemotherapy was classified in regimens of use based on chemotherapy combinations. OS and PFS were determined after diagnosis and after chemotherapy. Healthcare utilization was assessed in the year before diagnosis and in the year after chemotherapy.

In total, 125 CLL patients received chemotherapy: 52 patients (42\%) started chemotherapy within 6 months and 73 patients $(58 \%)$ started chemotherapy $\geq 6$ months after diagnosis. Mean $( \pm S D)$ age was $67( \pm 10)$ years and $68 \%$ was male. About $50 \%$ had one treatment line and about $25 \%$ two lines of treatment. Chlorambucil was the most common type of first line chemotherapy. Prior diagnosis, $44 \%$ were hospitalized for any cause and $94 \%$ had at least one drug dispensing. After chemotherapy, this was $43 \%$ and $98 \%$, respectively. One-year survival rate after diagnosis was $94 \%$. Median PFS after first treatment line was 17 months for patients starting within 6 months and 27 months for patients starting $\geq 6$ months after diagnosis. In conclusion, most CLL patients receiving chemotherapy were treated with chlorambucil. One-year after initial diagnosis, $94 \%$ were still alive. Median PFS after first line chemotherapy ranged from 17 to 27 months, depending on the timing of chemotherapy.

\section{INTRODUCTION}

Chronic lymphoid leukemia (CLL) is a type of slow growing blood cancer that affects developing B-cell lymphocytes and accounts for approximately $30 \%$ of all lymphoid neoplasms and $12 \%$ of nodal lymphomas [1,2]. CLL primarily affects patients aged 60 and older and men are affected twice as often as women [3-5]. In Europe, the agestandardized incidence rate of CLL is 3.8 per $1,00,000$ person-years [5,6] and 5.1 per $1,00,000$ person-years in the US [3].

There is unmet need concerning the treatment of older patients with CLL. The chemotherapy combination rituximab, fludarabine, and cyclophosphamide is the standard therapy for fit patients younger than 65 years and has shown to prolong overall survival [7]. However, randomized trials failed to show this benefit in improved survival among elderly, less fit patients. Until recently, chlorambucil monotherapy was the standard first line treatment for this group of patients. However, chlorambucil monotherapy is shown not to be very effective in terms of progression-free survival 
[8-10]. Randomized trials have shown beneficial effects of the addition of a monoclonal anti-CD20 antibody to chlorambucil [11]. Therefore, new Dutch guidelines in 2015 recommend to treat less fit patients with chlorambucil in combination with a monoclonal anti-CD20 antibody as first line treatment [12]. New treatments, such as ibrutinib, and other novel agents are expected to be better tolerated and improve outcome in patients with CLL. This study describes chemotherapy exposure, healthcare utilization, overall and progression-free survival among patients diagnosed with CLL receiving chemotherapy.

\section{SUBJECTS AND METHODS}

\section{Data sources}

Data for this retrospective cohort study were obtained from the Eindhoven Cancer Registry (ECR) linked on a patient-level to the PHARMO Database Network covering an overlapping demographic region in the southeastern part of the Netherlands of approximately 1.2 million inhabitants. The construct and validity of the PHARMO-ECR cohort are described elsewhere [13].

The ECR is a population-wide registry which is maintained by the Comprehensive Cancer Centre Netherlands and collates records on all newly diagnosed cancer patients in the southeastern part of the Netherlands [14]. Trained registry personnel actively collect onsite data on all incident cancer cases, including patient characteristics, diagnosis, tumor staging, comorbidity at diagnosis and treatment received directly after diagnosis (e.g. chemotherapy (yes/no), radiation therapy and surgery).

The PHARMO Database Network is a population-based network of healthcare databases and combines data from different healthcare settings in the Netherlands. These different data sources are linked on a patient level through validated algorithms. For this study, the Hospitalization Database, the In-patient Pharmacy Database, the Out-patient Pharmacy Database and the Clinical Laboratory Database was used. Data collection period, catchment area and overlap between data sources differ.

\section{Study population}

Patients who were diagnosed with CLL (WHO International Classification of Diseases for Oncology $3^{\text {rd }}$ edition code (ICD-0-3 morphology): 9673) in the period January 1, 1998 to December 31, 2011 were selected. In order to determine whether these patients received chemotherapy, selected patients were required to have inpatient pharmacy data available. All of these patients have hospital data and out-patient pharmacy data available and a part of them have clinical laboratory data available. Eligible patients were followed from first diagnosis of CLL onwards and were censored at time of diagnosis of a primary malignancy other than CLL, end of data collection in the PHARMO Database Network (i.e. the patient moves out of the PHARMO catchment area), death or end of the study period (December 31, 2012), whichever occurred first. Diagnosis of another primary malignancy was defined as a hospitalization with a primary or secondary discharge diagnosis for a primary malignancy other than CLL or chemotherapy received after initial diagnosis not related to the treatment of CLL. Patients receiving chemotherapy after initial CLL diagnosis were included in the analysis.

\section{Chemotherapy exposure}

Chemotherapy information, including type of drug and date of administration, was obtained from the Out-patient Pharmacy Database and the In-patient Pharmacy Database based on Anatomical Therapeutic Chemical (ATC) code L01. Administered chemotherapies after initial diagnosis were classified in regimens of use based on the received chemotherapy combinations and sequences. Chemotherapy regimens per patient were stratified by line of therapy with switch to following line of therapy based on: 1) the start of a different type of chemotherapy agent or combination of chemotherapy than initially was started with or 2) an interruption between two chemotherapy regimens of more than 183 days. 


\section{Healthcare utilization}

Among patients with at least 12 months of history in the PHARMO Database Network prior to initial CLL diagnosis, healthcare utilization in the 12 months prior to initial CLL diagnosis was determined. In addition, for patients with at least 12 months of follow-up in the PHARMO Database Network after chemotherapy treatment, healthcare utilization in the 12 months after chemotherapy treatment was determined. Healthcare utilization included all-cause hospitalization and out-patient medication use.

\section{Overall survival and progression-free survival}

Overall survival was determined after initial CLL diagnosis and after chemotherapy treatment. In addition, progression-free survival was determined after the end date of the first line chemotherapy treatment. Patients fulfilling one of the following criteria were defined as having progression of the disease: 1) start of a different type of chemotherapy agent or combination of chemotherapy than initially was started with, 2) at least one increase in the number of blood lymphocytes by $50 \%, 3$ ) at least one decrease in Hgb level by more than $2 \mathrm{~g} / \mathrm{dl}$ or a $\mathrm{Hgb}$ of less than $10 \mathrm{~g} / \mathrm{dl}, 4$ ) at least one decrease in platelet counts by more than $50 \%$ or a platelet count of less than $100.000 / \mathrm{ul}$, after at least 3 months. Criteria $2-4$ could only be detected for part of the CLL patients.

\section{Statistical analysis}

Analyses were descriptive in nature. Patient characteristics, chemotherapy exposure, overall survival and progression-free survival are presented by timing of chemotherapy. Survival is shown in Kaplan-Meier curves. All data were analyzed using SAS programs organized within SAS Enterprise Guide version 4.3 (SAS Institute Inc., Cary, NC, USA) and conducted using SAS version 9.2.

\section{RESULTS}

\section{Baseline characteristics}

There were 393 patients diagnosed with CLL in the PHARMO-ECR cohort between 1 January 1998 and 31 December 2011 and with hospitalization data, in-patient pharmacy data and out-patient pharmacy data available. Of these, 125 patients (32\%) received chemotherapy after initial diagnosis, of which 52 patients (42\%) started chemotherapy within 6 months after initial diagnosis and 73 patients (58\%) started chemotherapy more than 6 months after initial diagnosis. Among patients starting chemotherapy more than 6 months after initial diagnosis, the median (IQR) time between initial diagnosis and start of chemotherapy was 741 (379-1285) days. The mean $( \pm$ SD) age of patients starting chemotherapy within 6 months after initial diagnosis was $69( \pm 11)$ years and the majority was male $(62 \%)$ (Table 1). Of the patients starting chemotherapy more than 6 months after initial diagnosis, the mean $( \pm \mathrm{SD})$ age was $66( \pm 10)$ years and $73 \%$ was male.

\section{Chemotherapy exposure}

Among CLL patients receiving chemotherapy, about 50\% had one treatment line and about $25 \%$ had two lines of treatment, irrespective of when chemotherapy started. Chlorambucil was the most common type of chemotherapy received as first and second line treatment $(71 \%$ and $48 \%$ respectively for CLL patients starting chemotherapy within 6 months after initial diagnosis, and $75 \%$ and 58\% respectively for CLL patients starting chemotherapy more than 6 months after initial diagnosis). The second most common type of chemotherapy received as first and second line treatment was R-CVP for CLL patients starting chemotherapy within 6 months after initial diagnosis $(13 \%$ and $15 \%$ respectively). Among CLL patients starting chemotherapy more than 6 months after initial diagnosis, fludarabine was the second most common type of chemotherapy received as first line treatment $(10 \%)$ and rituximab as second line treatment $(17 \%)$ 
(Table 2). Among those starting chemotherapy within 6 months after initial diagnosis, the median (IQR) duration of the first and second line was 100 (40-195) days and 150 (49-244) days, respectively. Among those starting chemotherapy more than 6 months after initial diagnosis, the median (IQR) duration of the first and second line was 85 (48-169) days and 89 (44-199) days, respectively.

\begin{tabular}{|c|c|c|c|}
\hline & $\begin{array}{l}\text { CLL patients } \\
\text { receiving } \\
\text { chemotherapy } \\
\mathrm{N}=125 \mathrm{n}(\%)\end{array}$ & $\begin{array}{l}\text { Starting chemotherapy } \\
\text { within } 6 \text { months after initial } \\
\text { diagnosis } \\
\mathbf{N}=\mathbf{5 2} \mathrm{n}(\%)\end{array}$ & $\begin{array}{l}\text { Starting chemotherapy more than } 6 \text { months } \\
\text { after initial diagnosis } \\
\qquad N=73 n(\%)\end{array}$ \\
\hline \multicolumn{4}{|l|}{ Age (years) } \\
\hline$<60$ & $22(18)$ & $8(15)$ & $14(19)$ \\
\hline $60-69$ & $50(40)$ & $16(31)$ & $34(47)$ \\
\hline $70-79$ & $37(30)$ & $19(37)$ & $18(25)$ \\
\hline$\geq 80$ & $16(13)$ & $9(17)$ & $7(10)$ \\
\hline Mean \pm SD & $67 \pm 10$ & $69 \pm 11$ & $66 \pm 10$ \\
\hline \multicolumn{4}{|l|}{ Gender } \\
\hline Male & $85(68)$ & $32(62)$ & $53(73)$ \\
\hline Female & $40(32)$ & $20(38)$ & $20(27)$ \\
\hline \multicolumn{4}{|l|}{$\begin{array}{c}\text { Year of } \\
\text { diagnosis }\end{array}$} \\
\hline 1998-2003 & $45(36)$ & $17(33)$ & $28(38)$ \\
\hline 2004-2006 & $37(30)$ & $14(27)$ & $23(32)$ \\
\hline 2007-2009 & $20(16)$ & $9(17)$ & $11(15)$ \\
\hline $2010-2011$ & $23(18)$ & $12(23)$ & $11(15)$ \\
\hline
\end{tabular}

Table 2: Number of treatment lines and type of chemotherapy among CLL patients.

\begin{tabular}{|c|c|c|}
\hline & $\begin{array}{r}\text { Starting chemoth } \\
\text { within } 6 \text { months af } \\
\text { diagnosis } \\
\mathrm{N}=52 \mathrm{n}(\%)\end{array}$ & $\begin{array}{l}\text { Starting chemotherapy more than } 6 \text { months after } \\
\text { initial diagnosis } \\
\qquad \begin{array}{l}\mathrm{N}=73 \mathrm{n}(\%)\end{array}\end{array}$ \\
\hline \multicolumn{3}{|c|}{ Number of treatment lines } \\
\hline 1 & $25(48)$ & $37(51)$ \\
\hline 2 & $12(23)$ & $18(25)$ \\
\hline 3 & $3(6)$ & $6(8)$ \\
\hline 4 & $4(8)$ & $6(8)$ \\
\hline$>4$ & $8(15)$ & $6(8)$ \\
\hline \multicolumn{3}{|c|}{$\begin{array}{c}\text { Type of chemotherapy } \\
\text { regimen }\end{array}$} \\
\hline First line & $\mathrm{N}=52$ & $\mathrm{~N}=73$ \\
\hline \multicolumn{3}{|c|}{ Combination therapy } \\
\hline CVP & $3(6)$ & $0(0)$ \\
\hline R-CVP & $7(13)$ & $2(3)$ \\
\hline $\mathrm{R}-\mathrm{CHOP}$ & $2(4)$ & $1(1)$ \\
\hline $\mathrm{FC}$ & $1(2)$ & $4(6)$ \\
\hline $\mathrm{R}-\mathrm{FC}$ & $1(2)$ & $1(1)$ \\
\hline \multicolumn{3}{|l|}{ Monotherapy } \\
\hline Chlorambucil & $37(71)$ & $55(75)$ \\
\hline Fludarabine & $0(0)$ & $7(10)$ \\
\hline Rituximab & $1(2)$ & $3(4)$ \\
\hline Second line & $\mathrm{N}=\mathbf{2 7}$ & $\mathrm{N}=36$ \\
\hline \multicolumn{3}{|c|}{ Combination therapy } \\
\hline CVP & $3(11)$ & $0(0)$ \\
\hline R-CVP & $4(15)$ & $2(6)$ \\
\hline R-CHOP & $2(7)$ & $0(0)$ \\
\hline FC & $1(4)$ & $3(8)$ \\
\hline $\mathrm{R}-\mathrm{FC}$ & $1(4)$ & $3(8)$ \\
\hline Monotherapy & & 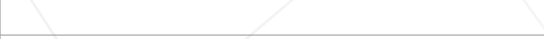 \\
\hline Chlorambucil & $13(48)$ & $21(58)$ \\
\hline Fludarabine & $1(4)$ & $1(3)$ \\
\hline Rituximab & $2(7)$ & $6(17)$ \\
\hline \multicolumn{3}{|c|}{$\begin{array}{l}\text { CVP=cyclophosphamide, vincristine; R-CVP=rituximab, cyclophosphamide, vincristine; } \mathrm{R}-\mathrm{CHOP}=\text { rituximab, } \\
\text { cyclophosphamide, doxorubicin, vincristine; } \mathrm{FC}=\text { fludarabine, cyclophosphamide; } \mathrm{R}-\mathrm{FC}=\text { rituximab, fludarabine, } \\
\text { cyclophosphamide. }\end{array}$} \\
\hline
\end{tabular}




\section{Healthcare utilization}

Of the 125 CLL patients, 117 patients (94\%) had at least 12 months of history prior to initial diagnosis. Of these, 52 patients $(44 \%)$ were hospitalized for any cause. Mean $( \pm$ SD) length of all-cause hospitalization stay among all patients (i.e. including patients without a hospitalization) was $4( \pm 9)$ days (Table 3 ). Regarding out-patient medication use, 110 patients (94\%) had at least one dispensing in the year prior to initial diagnosis. Mean $( \pm$ SD) number of dispensings among all patients (i.e. including non-users) was $20( \pm 18)$ (Table 4). There were 63 patients $(50 \%)$ with at least 12 months of followup after chemotherapy treatment. Of these, 27 patients (43\%) were hospitalized for any cause. Mean $( \pm \mathrm{SD})$ length of all-cause hospitalization among all patients was 6 $( \pm 17)$ days. There were 62 patients $(98 \%)$ with at least one dispensing in the year after chemotherapy treatment. The mean $( \pm \mathrm{SD})$ number of dispensings among all patients was $34( \pm 41)$.

\section{Survival}

One year after initial diagnosis, 94\% of CLL patients receiving chemotherapy were still alive (Figure 1A). Five years after initial diagnosis, 75\% of CLL patients receiving chemotherapy were still alive (Figure 1A). One year after the end of chemotherapy treatment, $77 \%$ were still alive (Figure 1B). This one-year survival rate was slightly higher among patients starting chemotherapy more than 6 months after initial diagnosis than for patients starting chemotherapy within 6 months after initial diagnosis $(77 \%$ vs. 71\%). The median progression-free survival from end of the first treatment line was 27 months for CLL patients starting chemotherapy within 6 months after initial diagnosis and 17 months for CLL patients starting chemotherapy more than 6 months after initial diagnosis (Figure 2).

Table 3: Hospitalizations in the year prior to initial diagnosis and in the year after chemotherapy treatment among CLL patients.

\begin{tabular}{|c|c|}
\hline & $\begin{array}{c}\text { CLL patients } \\
\mathbf{N}=125\end{array}$ \\
\hline In the 12 months prior to initial diagnosis & \\
\hline Number of patients with at least 12 months of history & $\mathrm{N}=117$ \\
\hline Number of hospitalized patients, $\mathrm{n}(\%)$ & $52(44)$ \\
\hline Total number of hospitalizations, $\mathrm{n}$ & 80 \\
\hline Total number of hospitalized days, $\mathrm{n}$ & 436 \\
\hline Mean \pm SD number of hospitalized days among all patients & $4 \pm 9$ \\
\hline In the 12 months after chemotherapy treatment & $\mathrm{N}=63$ \\
\hline Number of patients with at least 12 months of follow-up & $27(43)$ \\
\hline Number of hospitalized patients, $\mathrm{n}(\%)$ & 86 \\
\hline Total number of hospitalizations, $\mathrm{n}$ & 369 \\
\hline Total number of hospitalized days, $\mathrm{n}$ & $6 \pm 17$ \\
\hline Mean \pm SD number of hospitalized days among all patients & \\
\hline SD=standard deviation. & \\
\hline
\end{tabular}

Table 4: Out-patient medication use in the year prior to initial diagnosis and in the year after chemotherapy treatment among CLL patients.

\begin{tabular}{|c|c|}
\hline In the 12 months prior to initial diagnosis & $\begin{array}{c}\text { CLL patients } \\
\mathrm{N}=125\end{array}$ \\
\hline Number of patients with at least 12 months of history & $\mathrm{N}=117$ \\
\hline Number of users, $\mathrm{n}(\%)$ & $110(94)$ \\
\hline Total number of dispensings, $\mathrm{n}$ & 2,326 \\
\hline Mean \pm SD number of dispensings among all patients & $20 \pm 18$ \\
\hline In the 12 months after chemotherapy treatment \\
\hline Number of patients with at least 12 months of follow-up \\
\hline Number of users, $\mathrm{n}(\%)$ \\
\hline Total number of dispensings, $\mathrm{n}$ \\
\hline Mean $\pm S D$ number of dispensings among all patients \\
\hline SD=standard deviation
\end{tabular}


A

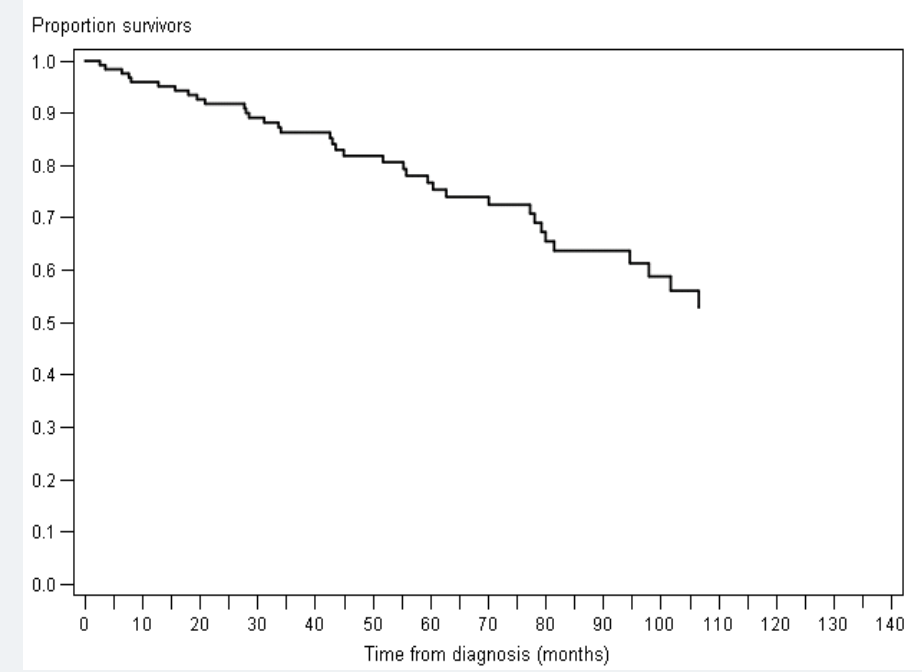

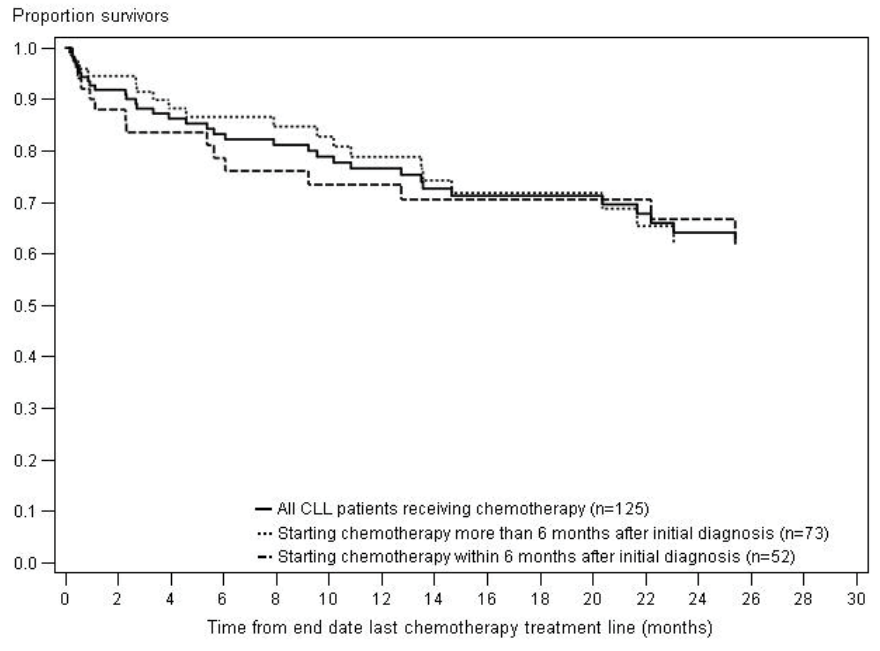

Figure 1: Survival after initial diagnosis (A) and after chemotherapy treatment (B) among CLL patients receiving chemotherapy.

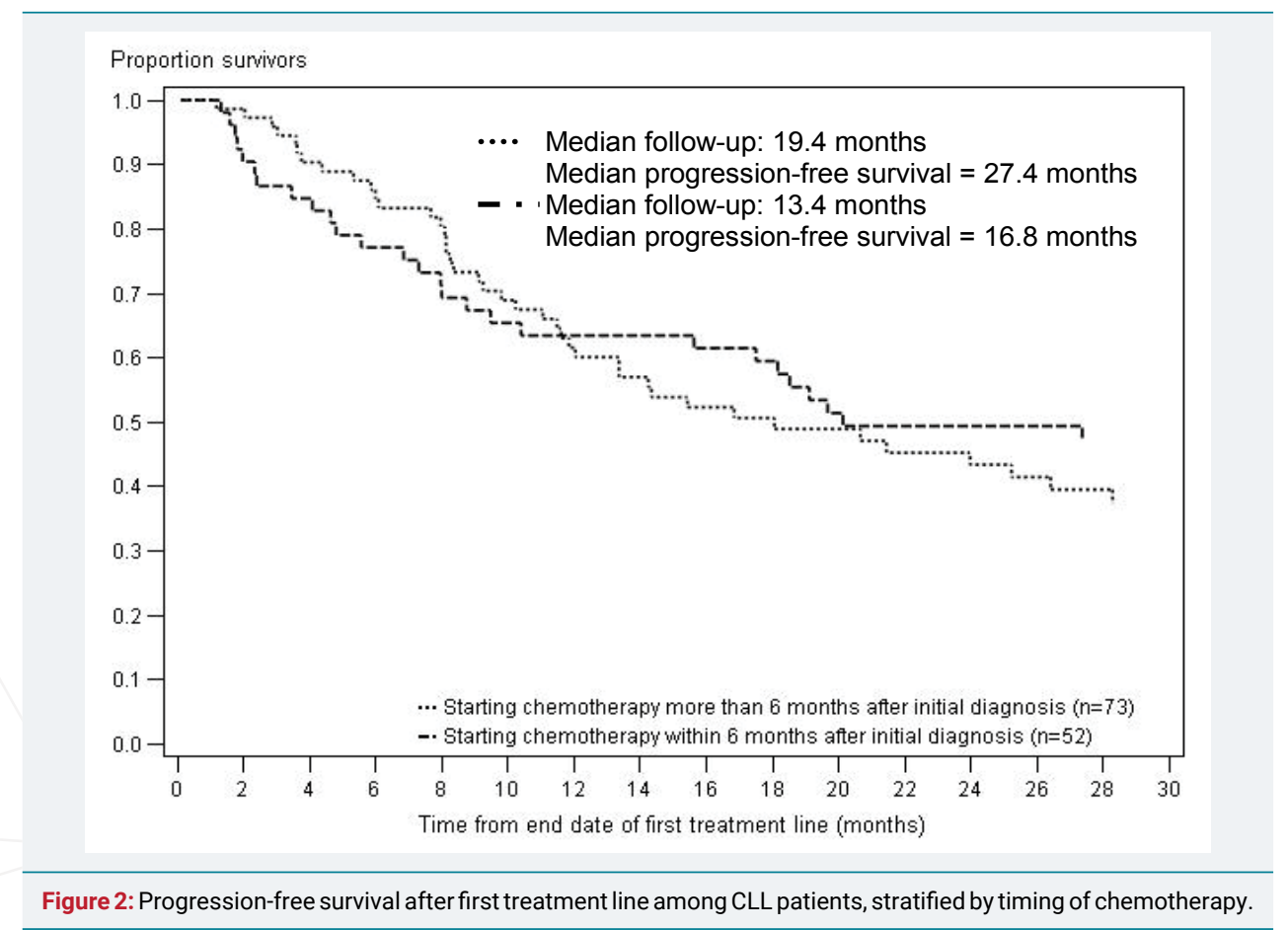

\section{DISCUSSION}

This retrospective cohort study has been performed to gain more insight in the treatment and outcomes of patients diagnosed with CLL in daily clinical practice. CLL patients receiving chemotherapy were selected from the PHARMO-ECR cohort. Age and gender of the study patients is similar to descriptions of CLL patients in the literature [3-5].

In order to investigate the outcomes and treatment specific for CLL, patients were censored at the time of diagnosis of other primary malignancy than CLL, defined as either receiving chemotherapy not related to the treatment of CLL or a hospitalization for another primary malignancy during follow-up. However, as probably not all patients are receiving chemotherapy or are hospitalized for a malignancy, some of the patients included in the study cohort may still be diagnosed with another malignancy. 
Of the CLL patients receiving chemotherapy, 58\% started chemotherapy more than 6 months after initial diagnosis. According to the guidelines, newly diagnosed patients with early stage disease do not need to be treated until they become symptomatic or display evidence of rapid progression of disease $[7,15]$. Patients starting chemotherapy within 6 months after initial diagnosis were slightly older than patients starting chemotherapy more than 6 months after initial diagnosis.

Approximately three-quarter of the CLL patients received chlorambucil as first line chemotherapy treatment, which is a commonly used chemotherapy type among less fit CLL patients. One year after initial diagnosis, 94\% of the CLL patients in this study were still alive and $75 \%$ after five years. A previous study has shown increased survival rates for CLL patients over the years. Five-year relative survival increased from $61 \%$ in $1989-1993$ to $70 \%$ 2004-2008 for males, and from $71 \%$ to $76 \%$ for females [5]. The one-year survival rate was slightly higher among patients starting chemotherapy more than 6 months after initial diagnosis than for patients starting chemotherapy within 6 months after initial diagnosis. Previous meta-analysis of randomized clinical trials (RCTs) did not show a difference in survival between patients starting early treatment and patients with a "watch and wait" period [16]. In a prospective, randomised, open-label, phase 3 study among psychically fit CLL patients, the addition of an antiCD20 monoclonal antibody to chemotherapy increased the proportions of patients achieving a complete remission and remaining free of progression for 3 years (3-year progression-free survival of $65 \%$ versus $45 \%$ ) [17]. In a more recent RCT among 781 CLL patients with a Cumulative Illness Rating Scale (CIRS) score higher than 6, combining chlorambucil with an anti-CD20 monoclonal antibody prolonged overall survival compared with chlorambucil monotherapy (hazard ratio for death, 0.41; 95\% CI, 0.23 to 0.74; $\mathrm{P}=0.002$ ) [18]. These RCTs suggest that chlorambucil alone is not as effective as chlorambucil in combination based on CLL survival rates. Recently, ibrutinib was approved in the EU for the treatment of adult CLL patients who have received at least one previous treatment, and for the treatment in front line of CLL patients who have genetic mutations in their cancer cells called $17 \mathrm{p}$ deletion or TP53 mutation [19]. Ibrutinib is an anticancer drug targeting B-cell malignancies and is a first-in-class oral covalent inhibitor of Bruton's tyrosine kinase (BTK). BTK is critical to the growth and survival of B-cells. Ibrutinib prevents BTK from functioning by killing the malignant B-cells and leaves healthy T-cells largely unaffected [20]. In a multicenter, open-label, phase 3 study among 391 CLL patients with relapsed or refractory disease, patients receiving ibrutinib showed significantly improved progression-free survival compared with patients receiving ofatumumab as assessed by Independent Review Committee (HR: 0.22 (95\% CI: 0.15-0.32), p<0.001) [21].

Elderly patients have not been studied extensively in many clinical trials and there is a large unmet need for treatment options in this high-risk group of CLL patients. More research is needed to show the benefit of more effective therapies in elderly less fit patients in order to improve survival.

\section{CONFLICT OF INTEREST}

Josephina G. Kuiper and Fernie J. A. Penning-van Beest are employees of the PHARMO Institute for Drug Outcomes Research. This independent research institute performs financially supported studies for government and related healthcare authorities and several pharmaceutical companies. Patience Musingarimi, Christoph Tapprich and Maren Gaudig are employees of Janssen.

\section{GRANT}

This work was supported by an unrestricted grant from Janssen Pharmaceutica NV. 


\section{ACKNOWLEDGEMENT}

Dr. Myrthe PP van Herk-Sukel, Manager Research Department and oncology expert at the PHARMO Institute for Drug Outcomes Research is kindly acknowledged for her input on the construction of this study and the interpretation of the results.

\section{REFERENCES}

1. Dighiero G, Hamblin TJ. Chronic lymphocytic leukaemia. Lancet. 2008; 371: 1017-1029. Ref.: https://goo.gl/BfTm5Q

2. Hoeller S, Zhou Y, Kanagal-Shamanna R, Xu-Monette ZY, Hoehn D, et al. Composite mantle cell lymphoma and chronic lymphocytic leukemia/small lymphocytic lymphoma: a clinicopathologic and molecular study. Hum Pathol. 2013; 44: 110-121. Ref.: https://goo.gl/J5UL6L

3. Dores GM, Anderson WF, Curtis RE, Landgren O, Ostroumova E, et al. Chronic lymphocytic leukaemia and small lymphocytic lymphoma: overview of the descriptive epidemiology. $\mathrm{Br} \mathrm{J}$ Haematol. 2007; 139: 809-819. Ref.: https://goo.gl/Smy7fF

4. Hallek M. Chronic lymphocytic leukemia: 2013 update on diagnosis, risk stratification and treatment. Am J Hematol. 2013; 88: 803-816. Ref.: https://goo.gl/YUDyiu

5. Van den Broek EC, Kater AP, van de Schans SA, Karim-Kos HE, Janssen-Heijnen ML, et al. Chronic lymphocytic leukaemia in the Netherlands: trends in incidence, treatment and survival. 1989-2008. Eur J Cancer. 2012; 48: 889-895. Ref.: https://goo.gl/hm2H7y

6. Sant M, Allemani C, Tereanu C, Capocaccia R, Visser O, et al. Incidence of hematologic malignancies in Europe by morphologic subtype: results of the HAEMACARE project. Blood. 2010; 116: 3724-3734. Ref.: https://goo.gl/PH8YGM

7. Hallek M, Cheson BD, Catovsky D, Caligaris-Cappio F, Dighiero G, et al. Guidelines for the diagnosis and treatment of chronic lymphocytic leukemia: a report from the International Workshop on Chronic Lymphocytic Leukemia updating the National Cancer Institute-Working Group 1996 guidelines. Blood. 2008; 111: 5446-5456. Ref.: https://goo.gl/cDQHGV

8. Hillmen $P$, Skotnicki $A B$, Robak $T$, Jaksic B, Dmoszynska $A$, et al. Alemtuzumab compared with chlorambucil as first-line therapy for chronic lymphocytic leukemia. J Clin Oncol. 2007; 25: 56165623. Ref.: https://goo.gl/vWMZZh

9. Rai KR, Peterson BL, Appelbaum FR, Kolitz J, Elias L, et al. Fludarabine compared with chlorambucil as primary therapy for chronic lymphocytic leukemia. N Engl J Med. 2000; 343: 1750-1757. Ref.: https://goo.gl/uMa8kv

10. Woods B, Hawkins N, Dunlop W, O'Toole A, Bramham-Jones S. Bendamustine versus chlorambucil for the first-line treatment of chronic lymphocytic leukemia in England and Wales: a cost-utility analysis. Value Health. 2012; 15: 759-770. Ref.: https://goo.gl/ZGnyWi

11. Hillmen $P$, Gribben JG, Follows GA, Milligan D, Sayala HA, et al. Rituximab plus chlorambucil as firstline treatment for chronic lymphocytic leukemia: Final analysis of an open-label phase II study. J Clin Oncol. 2014; 32: 1236-1241. Ref.: https://goo.gl/p9S6fG

12. Hovon CLWP. Richtlijnen Diagnostiek en Behandeling Chronische Lymfatische Leukemie/Small Lymphocytic Lymphoma (CLL/SLL) en Hairy Cell Leukemie (HCL). 2015.

13. Van Herk-Sukel MP, Van de Poll-Franse LV, Lemmens VE, Vreugdenhil G, Pruijt JF, et al. New opportunities for drug outcomes research in cancer patients: the linkage of the Eindhoven Cancer Registry and the PHARMO Record Linkage System. Eur J Cancer. 2010; 46: 395-404. Ref.: https://goo.gl/UoSvv8

14. Netherlands Comprehensive Cancer Organisation. [www.netherlandscancerregistry.nl]

15. Eichhorst B, Dreyling M, Robak T, Montserrat E, Hallek M, et al. Chronic lymphocytic leukemia: ESMO Clinical Practice Guidelines for diagnosis, treatment and follow-up. Ann Oncol. 2011; 22: 50-54. Ref.: https://goo.gl/jvNg7K

16. Group CTC. Chemotherapeutic options in chronic lymphocytic leukemia: a meta-analysis of the randomized trials. J Natl Cancer Inst. 1999; 91: 861-868. Ref.: https://goo.gl/n7MGdY

17. Hallek M, Fischer K, Fingerle-Rowson G, Fink AM, Busch R, et al. Addition of rituximab to fludarabine and cyclophosphamide in patients with chronic lymphocytic leukaemia: a randomised, open-label, phase 3 trial. Lancet. 2010. 376: 1164-1174. Ref.: https://goo.gl/zvCCsF 
18. Goede V, Fischer K, Busch R, Engelke A, Eichhorst B, et al. Obinutuzumab plus chlorambucil in patients with CLL and coexisting conditions. N Engl J Med. 2014; 370: 1101-1110. Ref.: https://goo.gl/SwofbB

19. EMA. European public assessment report (EPAR) for Imbruvica. 2015.

20. Brown JR. Ibrutinib (PCI-32765), the first BTK (Bruton's tyrosine kinase) inhibitor in clinical trials. Curr Hematol Malig Rep. 2013; 8: 1-6. Ref.: https://goo.gl/Y2W993

21. Byrd JC, Brown JR, O'Brien S, Barrientos JC, Kay NE, et al. Ibrutinib versus ofatumumab in previously treated chronic lymphoid leukemia. N Engl J Med. 2014; 371: 213-223. Ref.: https://goo.gl/oam8 